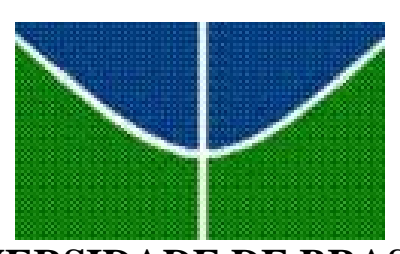

UNIVERSIDADE DE BRASÍLIA

Centro de Excelência em Turismo

Pós-graduação Lato Sensu

Curso de Especialização em Gastronomia e Saúde

\title{
ESTUDOS PRELIMINARES SOBRE O VALOR DA MARCA AGREGADO AO RESTAURANTE: O CASO DE UM RESTAURANTE DO TIPO GASTRONÔMICO DE BRASÍLIA.
}

\author{
Jane Mota Figueiredo \\ Prof ${ }^{a}$. Ms Verônica Cortez Ginani
}

Brasília - 2008 


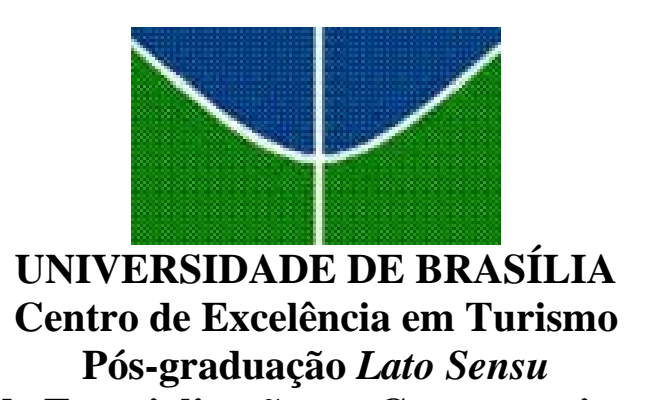

Curso de Especialização em Gastronomia e Saúde

\title{
ESTUDOS PRELIMINARES SOBRE O VALOR DA MARCA AGREGADO AO RESTAURANTE: O CASO DE UM RESTAURANTE DO TIPO GASTRONÔMICO DE BRASÍLIA.
}

\author{
Jane Mota Figueiredo \\ Prof ${ }^{a}$. Ms Verônica Cortez Ginani \\ Monografia apresentada ao Centro de \\ Excelência em Turismo - CET, da \\ Universidade de Brasília - UNB, como \\ requisito parcial à obtenção do grau de \\ Especialista em Gastronomia e saúde.
}


Figueiredo, Jane Mota

Estudos Preliminares Sobre o Valor da Marca Agregado ao Restaurante: O Caso de um Restaurante do Tipo Gastronômico de Brasília./ Jane Mota Figueiredo. - Brasília, 2008. $40 \mathrm{f} .:$ il.

Monografia (Especialização) - Universidade de Brasília, Centro de Excelência em Turismo, 2008.

Orientadora: Prof ${ }^{a}$. MsVerônica Cortez Ginani

1. Marca. 2. Identidade. 3. Perfil do consumidor. 


\section{UNIVERSIDADE DE BRASÍLIA}

Centro de Excelência em Turismo

Pós Graduação Lato Sensu

Curso de Especialização em Gastronomia e Saúde

Jane Mota Figueiredo

Aprovado por:

Professora orientadora: Ms. Verônica Cortez Ginani

Professora: Dra. Karin de Oliveira

Professora: Dra. Wilma Araújo

Brasília, 08 de agosto de 2008. 


\section{DEDICATÓRIA}

Sejamos como o sol que não usa recompensa, nem espera lucros, nem elogios ...simplesmente brilha. 


\section{AGRADECIMENTOS}

Agradeço à minha orientadora Verônica por ter sido tão gentil e sempre estar à disposição nas horas difíceis. Agradeço também por toda ajuda no encaminhamento do trabalho desde a escolha do tema até as considerações finais.

À minha família, por sempre me apoiar nas realizações dos meus projetos.

A Deus, por ter me proporcionado um caminho maravilhoso de realizações e aprendizado. 


\section{RESUMO}

O valor da marca passou a se constituir no diferencial de maior responsabilidade pela decisão de compra de um produto. É ele, em muitos casos, a única diferença entre um produto e outro. A marca é vislumbrada como sendo um suporte real da intangibilidade apontada como o elemento agregador das promessas dos benefícios junto do consumidor. O presente trabalho tem como objetivo analisar o valor atribuído pelo cliente à marca de um restaurante. Para isso, de forma específica busca-se entender o poder da marca no ciclo de vida de serviços de alimentação, investigar qual o perfil do consumidor e quanto a marca contribui para a fidelidade do cliente. Trata-se de um estudo de caso preliminar e inédito, pelo método indutivo, correlacionando em pesquisa descritiva, em forma de levantamento de dados, realizado em uma rede de restaurantes do tipo gastronômico localizado no Plano Piloto Brasília/DF. Utilizando um questionário auto preenchido como instrumento, foram coletados 35 questionários via correio eletrônico e utilizado o Excel para tratamento dos dados coletados. Análises descritivas mostraram que a maior parte da amostra é feminina, freqüenta os estabelecimentos a mais de um ano, é casado, têm pós-graduação e recebe acima de 12 salários mínimos por mês. Os resultados demonstram que os clientes efetivamente valorizam e consideram a oferta dos serviços da rede de restaurantes, como um valor agregado ao produto e como um diferencial da marca, confirmando-o como atividade necessária na cadeia de valor da empresa.

Palavras-chave: Marca, Cliente, Serviço, Marketing, Valor, Fidelidade. 


\begin{abstract}
The value of the mark passed if to constitute in the differential of bigger responsibility of the decision of purchase of a product. It is, in many cases, the only difference between a product and another one. The mark is glimpsed as being a real support of the pointed intangibilities as the aggregator element of the promises of the benefits next to the consumer. The present work has as objective to analyze the value attributed for the customer to the mark of a restaurant. For this, of specific form one search to understand the power of the mark in the cycle of life of feeding services, to investigate which the profile of the consumer and how much the mark contributes for the allegiance of the customer. One is about a study of preliminary and unknown case, for the inductive method, correlating in descriptive research, form datacollection, carried through in a net of restaurants of the gastronomic type located in the Plano Piloto - Brasília/DF. Using a filled auto questionnaire as instrument, 35 questionnaires had been collected saw e-mail and used Excel for treatment of the collected data. Descriptive analyses had shown that most of the sample is feminine, more than frequents the establishments the one year, is married, have after-graduation and receive above from 12 minimum wages for month. The results demonstrate that the customers effectively value and consider offer of the services of the net of restaurants, as an aggregate value to the product and as a differential of the mark, confirming it as necessary activity in the chain of value of the company
\end{abstract}

Keywords: Mark, Customer, Service, Marketing, Value, Allegiance. 


\section{LISTA DE GRÁFICOS}

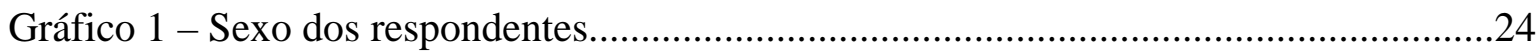

Gráfico 2 - Há quanto freqüenta um dos empreendimentos da rede................................24

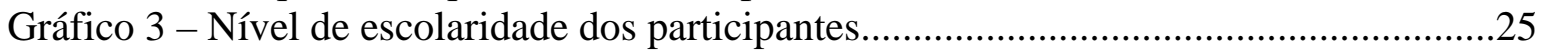

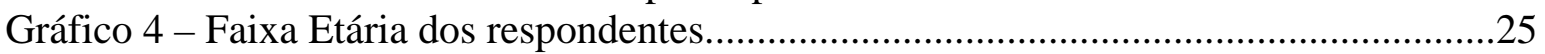

Gráfico 5 - Estado Civil dos respondentes....................................................................26

Gráfico 6 - Renda Mensal dos Respondentes..............................................................26 


\section{LISTA DE TABELA}

Tabela 1 - Porcentagem dos resultados da escala Likert...............................................23 


\section{SUMÁRIO}

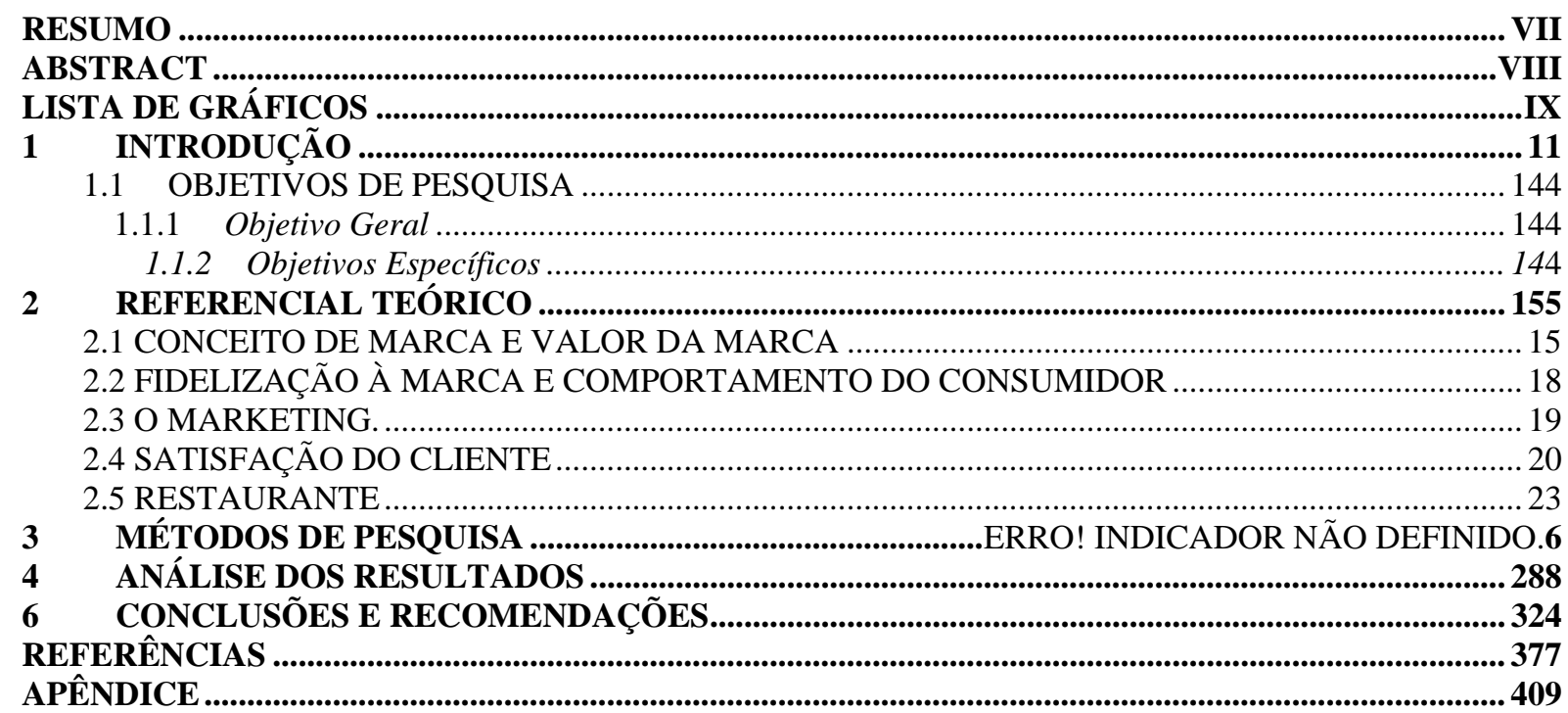




\section{INTRODUÇÃO}

Todos os clientes de restaurantes querem algo além da boa comida. Para tanto, os proprietários de serviços de alimentação buscam agregar o valor da marca ao produto e ao serviço, fazendo com que seus freqüentadores não sejam meros consumidores de comida, mas, sim, clientes da casa.

Nos últimos tempos, com mais precisão a partir da década de 1990, como conseqüente evolução dos processos de produção e comercialização iniciados com a Revolução Industrial, vários esforços e investimentos vêem sendo feitos no sentido de agregar serviços aos produtos. O objetivo estratégico é de distinção no mercado, por meio da criação de valor ao negócio (PAIXÃO, 2002).

Segundo Deleuze (2000) a marca ambiciona colonizar o planeta, conquistando os corações e as mentes por meio de sua onipresença e valorização incessante. Informam que as empresas têm alma, o que é efetivamente a notícia mais aterradora do mundo.

De acordo com Santos (2000), o marketing promove o culto obsessivo da marca, cuja presença se revela tanto na esfera pública quanto na privada. Para o autor, parece que na perspectiva do capitalismo global a única identidade que ainda faz sentido e deve ser preservada é a identidade da marca. Ou seja, o poder da marca, além de ser um fator identificador e controlador passa a desempenhar papel fundamental para o marketing de empresas de natureza diversificadas.

O presente trabalho justifica-se, pois visando compreender o gerenciamento de valor, faz-se pertinente abordagem do conceito e importância de valor agregado à marca. Através 
dessa evolução de tendências, percebe-se a necessidade de criação de valor para o cliente, com o objetivo de diferenciar a empresa e manter o cliente fiel à marca. Convencer o consumidor a optar pelo produto torna-se condição básica de sobrevivência em um mercado cada vez mais competitivo, dando-se maior ênfase às atividades de venda e tornando-as progressivamente mais agressivas. No entanto, vender sem garantir a satisfação do cliente para com o produto adquirido significa um risco muito alto para as empresas.

Aqui, vê-se a necessidade de avaliar empiricamente a real importância dessas ferramentas na equação de valor para o cliente e, conseqüentemente, avaliar se vale a pena mantê-las na cadeia de valor da empresa, buscando estudar a influência do serviço agregado a restaurantes, na decisão e fidelidade à marca.

Dentro deste contexto, há como evidenciar a relevância deste estudo sobre dois prismas distintos: da comunidade acadêmica e da rede gastronômica de restaurantes.

Um restaurante do tipo Gastronômico: “Caracteriza-se pela associação a um chefe de cozinha de renome e pelo cardápio com grande inventividade” (FONSECA, 2000).

De maneira geral, um restaurante refere-se a um local destinado ao preparo e distribuição de refeições e bebidas aos consumidores finais. É sabido que o principal foco em um restaurante é a alimentação e que as pessoas quando estão fazendo suas refeições não gostam de ser interrompidas ou incomodadas. Portanto, esse número de pessoas que come fora permitiu a explosão em quantidade e variedade de restaurantes e de serviços relacionados à comida; desde os populares fast-foods até os templos de alta cuisine (HECK, 2004). Restaurantes competem para atrair consumidores, e a mídia transforma os “cozinheiros” chefs - em celebridades glamourosas. Restaurantes recebem prêmios (estrelas), e surge a comida de griffe, que compete com a industrializada nas prateleiras dos supermercados.

Ainda segundo Heck (2004), comer deixa de ter apenas a sua função biológica óbvia, de nutrição para sobreviver, e entra para a categoria de lazer e entretenimento, assim como 
também passa a ser indicador de status e classe social, classificando e distinguindo gostos culinários. 


\subsection{Objetivos de Pesquisa}

\subsubsection{Objetivo Geral}

Analisar o valor da marca no caso de uma rede de restaurantes do tipo gastronômico em Brasília.

\subsubsection{Objetivos Específicos}

- Entender o poder da marca ao se gerenciar um estabelecimento comercial;

- Investigar qual o perfil do consumidor da marca pesquisada.

- Avaliar a percepção do consumidor em relação à marca estudada. 


\section{REFERENCIAL TEÓRICO}

\subsection{Conceito de marca e valor da marca}

A marca, nos últimos tempos, ganhou autonomia e importância devida, deixando de ser associada apenas ao nome e ao logotipo do produto. Atualmente a marca engloba outros conceitos como a imagem, a notoriedade, a personalidade e as associações que se manifestam tão complexos quanto o primeiro. Assim, a marca é vislumbrada como sendo um "suporte real da intangibilidade apontada como o elemento agregador das promessas dos benefícios junto do consumidor” (AZEVEDO, 2003).

Pode-se entender por marca, como um sinal ou conjunto de sinais susceptíveis de representação gráfica, nomeadamente palavras, incluindo nomes de pessoas, desenhos, letras, números, sons, a forma do produto ou da respectiva embalagem, desde que sejam adequados a distinguir os produtos ou serviços de uma empresa dos de outras empresas.

Salzer-Mörling e Strannegard (2004) entendem por marca uma produção e distribuição de símbolos que necessitam ser consumidos, contextualizados e mobilizados de modo a tornarem-se significativos.

A palavra marca pode significar diferentes coisas, como: instrumento legal, um logo, a companhia, a identidade de um sistema, a imagem na mente do consumidor, a personalidade do produto, a relação entre a companhia e os consumidores, valor adicionado a uma ferramenta, tudo depende do ponto de vista (CHERNATONY, 1999).

Nos dias de hoje, a marca é o único valor intelectual que a legislação reconhece como sendo uma propriedade eterna, pois até as patentes e os direitos autorais têm um prazo de validade 
Para Stalimir Vieira (2002, p. 16-17), é uma ilusão acreditar que um conceito de marca pode ser eficiente a partir de definições artificiais, criadas fora do contexto ideológico da empresa. Nenhum plano, por mais tecnicamente justificado, se sustenta sem considerar que toda marca nasce impregnada de um ideal. E ele será a essência do seu sucesso ou o mal congênito a comprometê-lo para sempre. Isso não significa, necessariamente, que a marca portadora de males congênitos também cresce. E seus males congênitos se não corrigidos, crescem junto, podendo se converter num problema cada vez maior.

Ou seja, a marca, pode assumir valor superior a todo imobilizado que uma empresa possui, e que também uma marca portadora de males congênitos também cresce.

De acordo com Tavares (1998, p. 194), o valor da marca tem sido visto sob uma variedade de perspectivas. Dependendo de qual é considerada, adiciona ou reduz valor para a empresa, para os canais de distribuição e para o consumidor. Esse valor pode também aumentar ou diminuir ao longo do tempo e ser menos ou mais extensível a outras categorias, conforme já abordado. Pode ser firmemente ligado à identidade geral da empresa ou completamente separado e pode ser mais ou menos volátil às forças mercadológicas ou competitivas

Consoante Gobé (2002) afirma que a marca é envolvida por atributos emocionais em sua essência. Diz: "Por emocional, quero dizer como uma marca se comunica com os consumidores no nível dos sentidos e das emoções”

De acordo com Strunk (2001), grande parte das nossas decisões de compra são feitas por impulso, de forma irracional, instintiva. Se temos dinheiro, compramos as marcas com as quais nos relacionamos emocionalmente. Cada marca é como uma pessoa que teve sua personalidade própria cuidadosamente criada e desenvolvida. 
Para quem abordar a questão da marca é falar em emoções, pelo que no processo de concepção e divulgação de uma marca é necessário compreender o que motiva a opção de compra e é fundamental utilizar uma imagem (mental e simbólica), adequada aos sentimentos do consumidor. (MARTINS, 1999)

Na construção da marca é necessário trabalhar com grupos de imagens representativas das emoções humanas, que tenham significado simbólico confirmado em pesquisas com o consumidor.

De acordo com Pinho (1996), as marcas não nascem gigantescas e conhecidas, razão pela qual sempre existe um incessante trabalho de marketing direcionado a elas. Pinho afirma que:

(...) a publicidade exerce o papel de auxiliar o consumidor a perceber o valor e qualidade de uma marca, produto ou serviço. A comunicação publicitária pode ser utilizada na construção do conhecimento do nome da marca, na percepção de suas qualidades, na formação de associações e até mesmo, na fidelidade dos consumidores. Segundo o autor, todas essas formas contribuem para a construção da imagem da marca pelo fato do seu alto poder de penetração e convencimento que a mídia exerce hoje junto aos clientes.

É relevante prestar atenção no conceito de “comportamento preferencial”. Pode-se dizer que um organismo apresenta um comportamento preferencial positivo em relação a um objeto ou situação, quando atua de modo a manter a presença desse objeto ou situação, ou de modo a criar esse objeto ou situação quando não está presente.

Entende-se que a verdadeira raiz do valor da marca é o trabalho humano, mais precisamente a quantidade de trabalho necessário à produção de um determinado bem, tempo esse determinado exatamente pelos meios e formas de produção numa relação de produção social determinada. Ou seja, todos os colaboradores criam valor numa empresa, ainda que de forma distinta, e, conseqüentemente, motivados e liderados de forma diversa (MARX, 1989)

Segundo Porter (1989), as empresas são um conjunto de atividades executadas para projetar, produzir, comercializar, entregar e sustentar seu produto, e o modo como a empresa 
executa suas atividades individuais é um reflexo de sua história, de sua estratégia e método de implementação. O valor seria, nesta ótica, o montante que os compradores (consumidores) estão dispostos a pagar pelo que uma empresa lhes fornece.

Segundo Mahfood (1994, p.26), o cliente prejudicial à organização é o que está insatisfeito e não reclama. Ter clientes insatisfeitos e não ter a oportunidade de ouvi-los talvez seja uma das piores ocorrências para uma organização. O cliente insatisfeito pode trazer para dentro da empresa novas idéias: clientes insatisfeitos mostram, muitas vezes, o que acontece de errado em processos que existem dentro da empresa e que nunca foram revistos.

Elevar o desempenho dos consumidores, significa aumentar seu nível de satisfação ou atender melhor suas necessidades (PORTER, 1989)

\subsection{Fidelização à marca e comportamento do consumidor}

Os compradores leais à marca tendem a não sair de seus padrões de compra em função de promoção de marcas concorrentes. A propaganda é capaz de aumentar a lealdade de marca.

Pinho (1996) ressalta que ao “[...] adquirir um produto, o consumidor não compra apenas um bem. Ele compra todo o conjunto de valores e atributos da marca”. Em função da sua importância a marca pode sustentar a empresa e manter a lealdade dos clientes.

Engel (2000, p.4) afirma, “Comportamento do consumidor pode ser definido como as atividades diretamente envolvidas em obter, consumir e dispor de produtos e serviços, incluindo os processos decisórios que antecedem e sucedem estas ações”.

Afirma KOTLER (1998) que: “A área de comportamento do consumidor estuda como indivíduos, grupos e organizações selecionam, compram, usam e dispõem de bens, serviços, idéias ou experiências para satisfazer as suas necessidades e desejos” 


\subsection{O Marketing.}

Conforme Kotler (1998) o conceito mais básico inerente ao marketing é o das necessidades humanas, que são estados de carência percebida, de privação de alguma satisfação básica. Ainda segundo o autor os desejos são carências por satisfações específicas para atender às necessidades, e são moldados pela cultura e pelas características pessoais. As demandas consistem nos desejos respaldados pela habilidade e disposição de comprá-los.

Os profissionais de marketing que almejam cada vez mais aumentar a lucratividade e conquistar a fidelização dos clientes precisam ter atenção quanto às atividades que antecedem a compra do serviço e aos motivos que levam a tomada de decisão dos consumidores por aquela determinada empresa. De acordo com Bateson e Hoffman (2001), essa decisão é acompanhada por um conjunto de expectativas sobre o desempenho do serviço. Além disso, a avaliação pós-compra, que acontece enquanto o consumidor interage com o prestador de serviços, resulta na satisfação ou insatisfação.

Em Kotler (2000) encontra-se a seguinte definição “o marketing como o processo social e gerencial através do qual indivíduos e grupos obtêm aquilo que desejam e de que necessitam, criando e trocando produtos e valores uns com os outros”. Pode-se entender esta definição, examinando-se os seguintes termos importantes: necessidades, desejos, demandas, produtos, valor, satisfação, qualidade, troca, transações, relacionamentos e mercados.

Entre as diversas definições existentes de marketing, a mais atual é aquela que considera todos os avanços que foram sendo acrescentados ao longo dos anos. Essa definição registra que "marketing é a área do conhecimento que engloba todas as atividades concernentes às relações de troca, orientadas para a satisfação das necessidades dos consumidores, e considerando sempre o ambiente de atuação e o impacto que essas relações causam no bem-estar da sociedade”. O marketing tem influência tanto nas organizações como na sociedade. Atualmente, não é suficiente apenas satisfazer as necessidades e os desejos dos 
consumidores, é preciso que a organização respeite os seus parceiros, e o ambiente, e principalmente tenha e pratique a responsabilidade social (LAS CASAS, 2006),

Conforme Brown (2001), Um relacionamento duradouro é mutuamente combinado e ambas as partes se tornam extremamente ligadas. Nesse ponto, a fidelidade se baseia nos altos graus de satisfação e o cliente fica intimamente envolvido com a empresa. Conforme o casamento prossegue, as ligações entre o cliente e a empresa são gradualmente fortificadas. Aqui o sentimento de satisfação do cliente aumenta e, com ele, a fidelidade à empresa.

\subsection{Satisfação do cliente}

Quando as organizações procuram atender a desejos e necessidades dos clientes, baseadas nas expectativas, elas estão procurando atingir a satisfação destes. Kotler (2000, p. 58) afirma que, a satisfação consiste na sensação de prazer ou desapontamento resultante da comparação do desempenho percebido de um produto em relação às expectativas do comprador. Como esta definição deixa claro, a satisfação é função do desempenho percebido e das expectativas do cliente. Se o desempenho ficar longe das expectativas, o consumidor estará insatisfeito. Se o desempenho atender as expectativas, ele se sentirá satisfeito, e se superarmos as expectativas ele estará altamente satisfeito.

De acordo com Lovelock e Wright (2005, p.25), [...] as empresas criam valor oferecendo os tipos de serviços que os clientes necessitam, apresentando apuradamente suas capacidades e realizando-as de maneira agradável e conveniente por um preço justo. Com isso pode-se aferir que a empresa que quer vender mais deve ter qualidade no atendimento, disponibilidade de produtos e serviços, garantia pós-venda e preços competitivos e atraentes numa demonstração de esforço constante de manutenção de seus clientes. 
A satisfação do cliente com relação a qualquer serviço ou produto, medida por qualquer critério que seja, mostrará uma distribuição que varia desde a insatisfação extrema até a satisfação total. Portanto, a conquista acontece no momento do atendimento que se caracteriza pelo contato entre vendedor e comprador. Em função desse contato, o comprador cria uma imagem, que associa à pessoa que lhe prestou o serviço e à empresa (DEMING, 1990),

Satisfação é o nível de sentimento de uma pessoa, resultante da comparação do desempenho de um produto em relação a suas expectativas. Dessa maneira, toda empresa deve se assegurar de que a qualidade de seus serviços satisfaça constantemente às exigências de seus clientes (KOTLER, 1996)

Satisfação consiste na sensação de prazer ou desapontamento de uma pessoa resultante da comparação entre o desempenho (ou resultado) percebido de um produto ou suas expectativas. Se o desempenho não atende as suas expectativas o cliente fica insatisfeito. Quando a empresa participa ativamente, ela se antecede ao cliente para saber o nível de satisfação com o produto ou serviço prestado. De acordo com Cobra (2000) os clientes são disputados a peso de ouro no mercado de bens e consumo.

Barnes (2002), afirma que um dos fatores determinantes da satisfação é o tratamento que o cliente recebe ao interagir com a organização. Ao levar em consideração como as pessoas se sentem todas as vezes que há um contato, a empresa estará se diferenciando da concorrência pelo aspecto mais intangível da satisfação, a emoção do contato. Ainda conforme o autor citado,

Se soubéssemos até que ponto o cliente é levado a se sentir descontraído, bem-vindo, satisfeito, à vontade e agradavelmente surpreso, ou, por outro lado, frustrado, decepcionado, confuso, negligenciado e sem importância, conheceríamos bem a situação do relacionamento com esse cliente. (BARNES, 2002, p. 64), 
Quando se estabelece bom relacionamento e comunicação com os clientes, eles desejarão continuar a realizar negócios com a empresa e irá recomendá-la a outras pessoas.

Conforme Brown (2001) “(...) clientes são propagandas ambulantes para a empresa, elogiando e recomendando-a para outros”, simplesmente pelo fato de terem tido suas expectativas superadas e por sentirem maior confiança na hora de adquirir o produto ou serviço.

Este mesmo autor aponta que se deve diferenciar o cliente de acordo com o valor que os mesmos representam, com a seguinte afirmação,

De acordo com o autor o estágio em que uma empresa opera tem um impacto significativo na maneira como ela trata os clientes. Quando uma empresa está na fase de aquisição de clientes, ela tem como enfoque a construção de uma base de clientes; na fase de retenção, seu enfoque muda para a maximização do relacionamento com o mesmo; na última fase, a fase de atendimento estratégico, a empresa seleciona clientes potenciais para ela, e gera com eles uma relação de dependência empresa-consumidor.

Considera-se que os clientes estão cada vez mais exigentes com os produtos e serviços, e que assumem menos compromissos de retornar à organização se o que é oferecido não satisfaz as suas necessidades nem atende às suas expectativas. Confiança, respeito mútuo e um sentimento básico de integridade no ambiente de trabalho fará com que todos os funcionários da empresa manifestem consciência de que todos os clientes devem ser atendidos com qualidade, visando o alcance da satisfação dos mesmos. (KOTLER, 1996)

Aqui se entende que a qualidade está completamente relacionada com a satisfação dos consumidores de produtos ou serviços, e considerando o consumidor como o maior bem de qualquer empresa, conclui-se que a razão de ser da empresa é a busca incessante da satisfação dos desejos e necessidades dos seus clientes. 
Paladini (1990, p.26) afirma que “o grau com o qual um produto específico atende às necessidades de consumidores específicos”. Entende que, as empresas que oferecem aos clientes o que eles precisam em termos de produtos e de serviços com qualidade têm mais chance de prosperar nesse mercado competitivo e, para isso, estão revendo seus conceitos e alterando suas práticas por meio de treinamento de seus executivos, gerentes e supervisores, em programas comportamentais e de atualização tecnológica.

Quando se estabelece bom relacionamento e comunicação com os clientes, eles desejarão continuar a realizar negócios com a empresa e irá recomendá-la a outras pessoas.

\subsection{Restaurante}

Os restaurantes representam um papel importante no estilo de vida das pessoas. No mundo contemporâneo comer fora é uma das atividades sociais favoritas, pois comer sempre foi um passatempo importante ou uma atividade social prazerosa (WALKER e LUNDBERG, 2003)

A Revolução Industrial, iniciada em meados do século XIX, transformou a maneira de viver da sociedade. A concentração em cidades gerou novas necessidades, entre as quais a de alimentar as pessoas em locais apropriados. Além disso, estes locais foram sofrendo uma diversificação muito grande (restaurantes, lancherias, pizzarias, bares, dentre outros) exatamente para atender aos anseios e necessidades dos diferentes segmentos de mercado que se formaram (DAYAN, 1990)

Spang (2003) abre o livro dando várias definições encontradas para restaurante nos mais célebres dicionários franceses daquela época, o "Furetière" e o "Dictionnaire de l'Academie Française": "restaurant" era uma sopa. Isso mesmo. Um caldo de carne 
revigorante, feito para pessoas debilitadas ou fracas do peito. Nas novas casas especializadas em servir o consomé, as pessoas que sentiam fraqueza poderiam comer tranqüilamente.

A palavra "restaurateur", nome pelo qual hoje é conhecido qualquer dono de restaurante, designava o cozinheiro encarregado de fazer o caldo. Esse era quase um comércio ilegal. As ligas ou guildas de artesãos impediam que seus membros tivessem outros tipos de comércio que não fossem oficiais e regulamentados. Spang lembra que durante o Antigo Regime, as possibilidades de comer fora do ambiente doméstico eram limitadas. Além das tabernas, entre os estabelecimentos que precederam os restaurantes havia os hotéis e as pensões. Nos hotéis particulares, os visitantes tinham de desembolsar muito mais para se sentar à "table d'hôte", expressão que pode ser traduzida como mesa do anfitrião. Nesses locais, infelizmente o hóspede ou comensal não tinha direito à escolha de cardápio e deveria se adaptar às norma da casa. Também eram rígidos os horários das refeições e todos comiam juntos.

De acordo com Powers e Barrows (2004, p. 62), o termo restaurant, que significa “restaurador de energia” vem do francês. Este termo é usado desde meados do século XVIII, descrevendo os locais públicos que ofereciam sopa e pão. Por outro lado, Spang (2003) atribui a Marthurin Roze de Chantoiseau a criação destes paraísos dos sabores.

Independente da origem, o fato é que o restaurante faz parte do cotidiano da maioria das populações em todo o mundo. Pois, há muitos tipos de restaurantes, o que dificulta distinguir um modelo que se ajuste a todos, e muitos restaurantes não possuem conceitos claros a seu respeito (POWERS E BARROWS, 2004)

Ainda Powers e Barrows (2004) afirmam que os atendentes contribuem decisivamente para o sucesso de um restaurante. Esta é uma característica importante para a satisfação do cliente, em conjunto com outros fatores, como, por exemplo, o reconhecimento de um garçom 
sobre preferências de um cliente. Particularmente restaurantes internacional ${ }^{1}$, prezam pela individualização do atendimento, buscando aproximar ao máximo a clientela.

Os autores Walker e Lundberg (2003) em sua obra “O restaurante: conceito e operação”, definem os restaurantes sofisticados como os que possuem um ambiente luxuoso e confortável e que geralmente possuem talheres de prata de boa qualidade, louças, cristais, toalhas de linho, assim como a mobília, que inclui quadros com detalhes arquitetônicos.

Um restaurante pode ser definido conforme (Holanda, 1986, p.573) "Do francês restaurant nome duma casa de pasto aberta em 1.767 em Paris. 1Estabelecimento comercial onde se preparam e servem refeições. 2- Lugar onde se servem refeições avulsas a certo número de pessoas: o restaurante duma fábrica, dum hospital, dum trem.”

O ramo de servir alimentação de forma coletiva não é para gente sem garra. Quem pensa em abrir um restaurante deve ter riqueza de experiência para este tipo de negócio. Deve-se ter capacidade de assumir riscos, não tendo medo de desafios, conhecer bem o ramo, ter senso de organização, ser otimista e saber motivar-se. O mercado contemporâneo deve estimular a competitividade e as exigências dos consumidores, é indispensável ás empresas a reestruturação e adaptação a essa realidade. (WALKER e LUNDBERG, 2003)

Quando se estabelece bom relacionamento e comunicação com os clientes, eles desejarão continuar a realizar negócios com a empresa e irá recomendá-la a outras pessoas. O atendimento com excelência incrementa o marketing, porque motiva os clientes a difundirem bons comentários sobre os serviços e negócios a outros clientes potenciais.

\footnotetext{
${ }^{1}$ Restaurante Internacional: Estabelecimento comercial onde se preparam e servem refeições de outros paises.
} 


\section{MÉTODOS DE PESQUISA}

A pesquisa é um estudo de caso, pois faz análise sobre um ou poucos casos, sob o ponto de vista de seus integrantes, interpretando as suas relações com o ambiente pesquisado. Conforme Yin (1988), o estudo de caso não condiz a uma amostra da população, mas a uma região com prescrição sistêmica e proposições teóricas delimitadas. O estudo de caso facilita a análise de casos isolados e até polêmicos, mas a reprodução e a generalização de seus resultados ficam comprometidas caso cada etapa do estudo não seja efetivada de uma forma operacional, como sugere Yin (1988). Realizado pelo método indutivo por ser aquele que, ao partir de premissas menores pode-se chegar às generalidades. É importante ressaltar que a indução, antes de tudo, é uma forma de raciocínio ou de argumentação; portanto, forma de reflexão e não, de simples pensamento. Conforme Oliveira (1997, p. 60), “Apesar das grandes discussões levantadas no século XIX sobre o assunto, a indução é o método científico por excelência e, por isso mesmo, é o método fundamental das ciências naturais e sociais”. Correlacionando em pesquisa descritiva em forma de levantamento de dados que segundo Gil (1991), visa descrever as características de determinada população ou fenômeno ou o estabelecimento de relações entre variáveis. Envolve o uso de técnicas padronizadas de coleta de dados: questionário e observação sistemática. Realizado em um restaurante do tipo gastronômico localizado no Plano Piloto - Brasília/DF.

A seleção do restaurante foi realizada com o auxílio da revista VEJA Brasília dos anos de 2005, 2006, 2007 e 2008. Foram utilizados os seguintes critérios:

Reconhecimento pela mídia em relação à qualidade (premiado pela revista VEJA);

Possuir mais de um estabelecimento no ramo (rede); 
Possuir uma grife relacionada com o chef de cozinha, demonstrando o valor/poder da marca.

Após a seleção do estabelecimento, foram aplicados 100 questionários (ANEXO) no período de 13 a 20 de julho de 2008 a clientes dos estabelecimentos que compõem o grupo estudado. Os questionários foram enviados via correio eletrônico e somente 35 questionários foram respondidos.

A formulação do questionário obedeceu ao modelo utilizado por Oliveira (2006), que optou por utilizar a escala Likert, a qual, segundo Malhotra (2001), é uma técnica de escalonamento não comparativo, de cinco categorias variando de "discordo totalmente” a “concordo totalmente”, a partir das afirmações apresentadas. Esta escala foi utilizada para as variáveis que não eram categóricas. Foi escolhida a escala de cinco pontos devido à sua utilização por Yoo e Donthu (2001) e à sua reaplicação em vários outros estudos de marcas, como, por exemplo, Baldauf, Cravens e Binder (2003); sendo realizada a adaptação necessária para o tipo de empreendimento estudado. O tratamento dos dados foi feito por Excell. 


\section{ANÁLISE DOS RESULTADOS E DISCUSSÃO}

De acordo com a aplicação do questionário, observou-se que o perfil da clientela que freqüenta a rede de restaurantes estudada, a maioria é do sexo feminino com $68 \%$ como mostrado no gráfico 1.

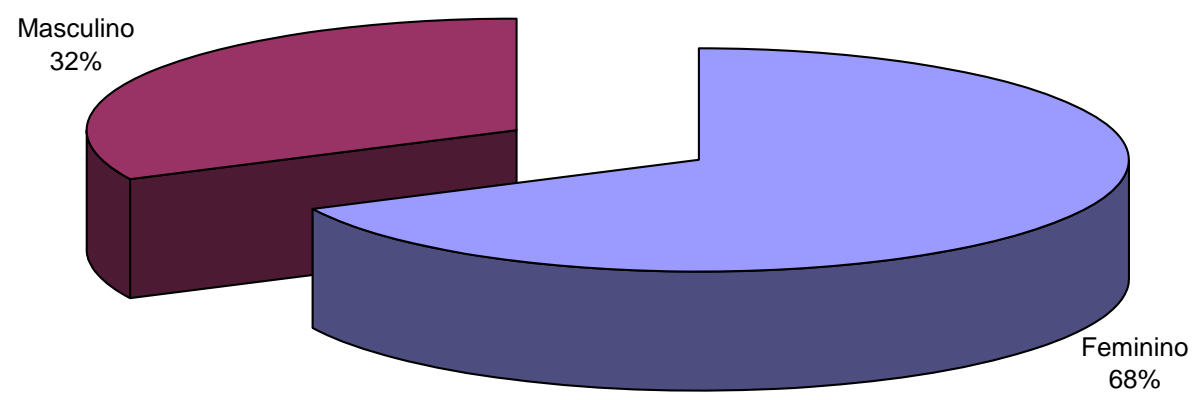

Gráfico 1 - Sexo dos respondentes Fonte: Elaborado pela autora em adaptação por Oliveira (2006)

A pesquisa mostrou que a grande maioria dos clientes da rede, freqüenta os estabelecimentos entre 1 a 5 anos - 50\%, conforme gráfico 2 . 


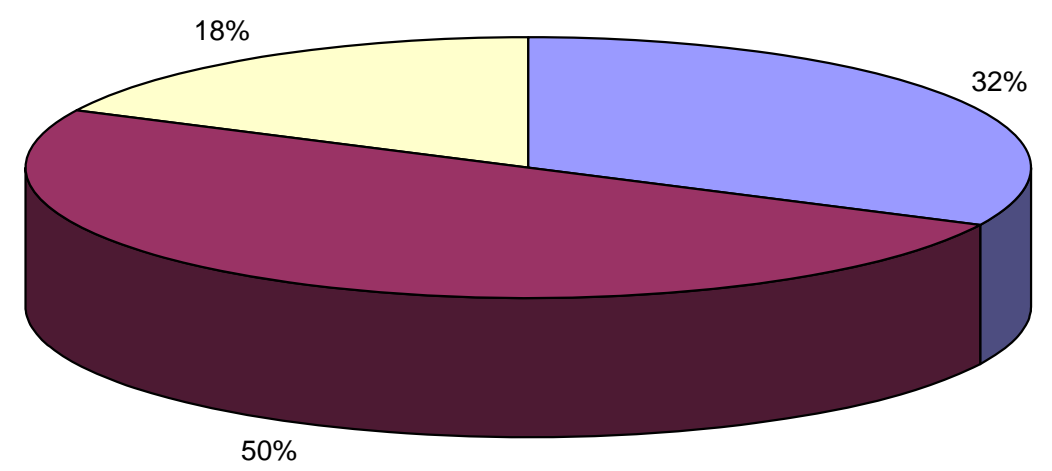

Gráfico 2 - Há quanto tempo frequenta um dos empreendimentos da rede Fonte: Elaborado pela autora em adaptação por Oliveira (2006).

Nos outros aspectos sociodemográficos avaliados, verificou-se que $44 \%$ dos respondentes tem pós-graduação, 38\% possui ensino superior completo e 15\% superior incompleto. Os respondentes com $2^{\circ}$ grau somou-se apenas $3 \%$ da amostra. Mostrando que o público que freqüenta a rede de restaurantes tem um alto grau de instrução conforme apresentado no gráfico 3. 


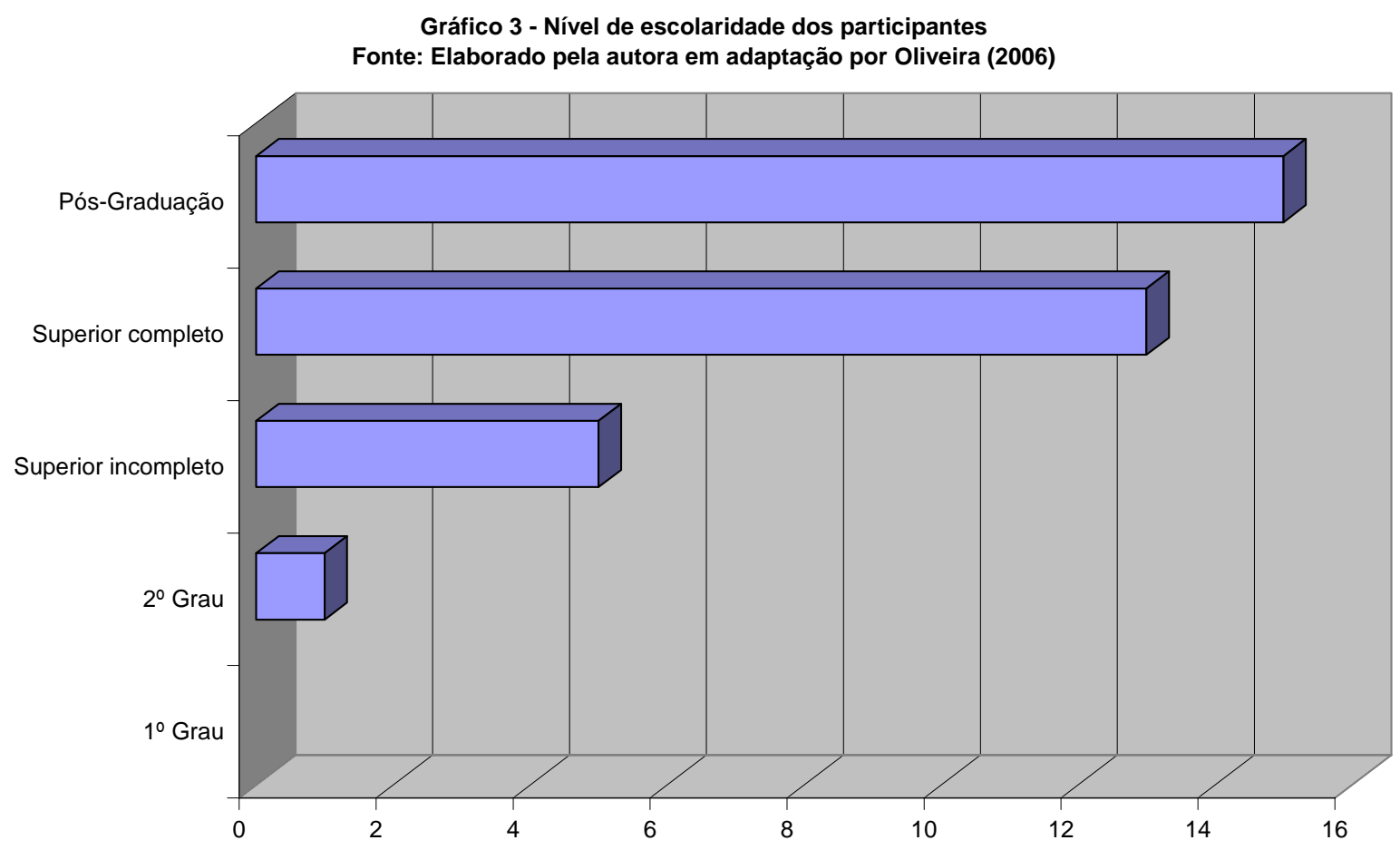

A idade dos respondentes mostrou que o público que freqüenta os estabelecimentos estão na faixa de 21 a 40 anos somando-se $85 \%$ dos clientes, mostrando um público jovem conforme gráfico 4.

Gráfico 4 - Faixa Etária dos respondentes

Fonte: Elaborado pela autora em adaptação por Oliveira

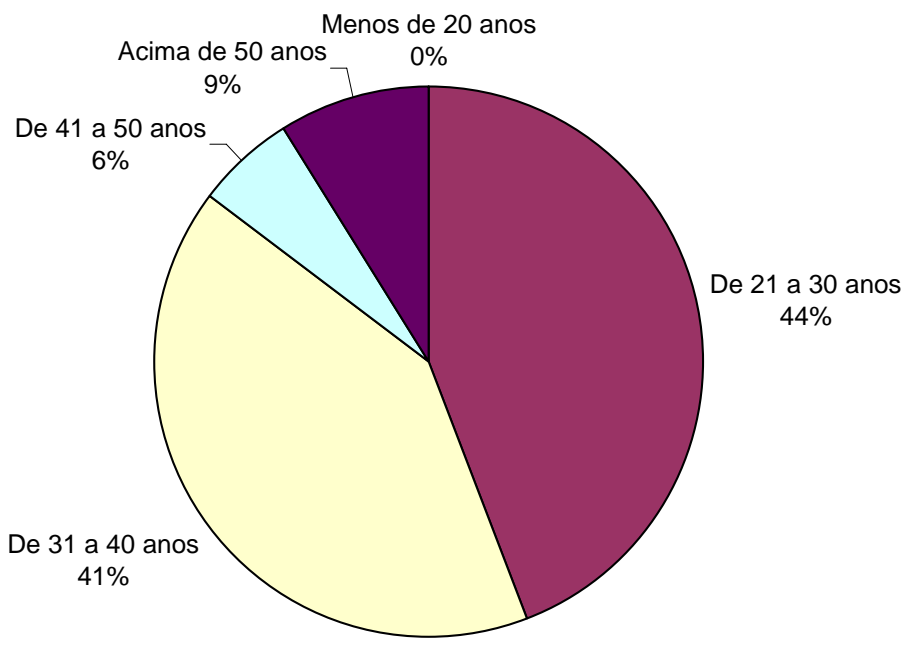


O estado civil do público que freqüenta a rede de restaurantes são a maioria casados ou vivem juntos com $42 \%$ da amostra da pesquisa seguido de $32 \%$ de separados ou divorciados e 26\% de solteiros. Não houve respondente viúvo (a) conforme gráfico 5.

Gráfico 5 - Estado Civil dos respondentes Fonte: Elaborado pela autora em adaptação por Oliveira

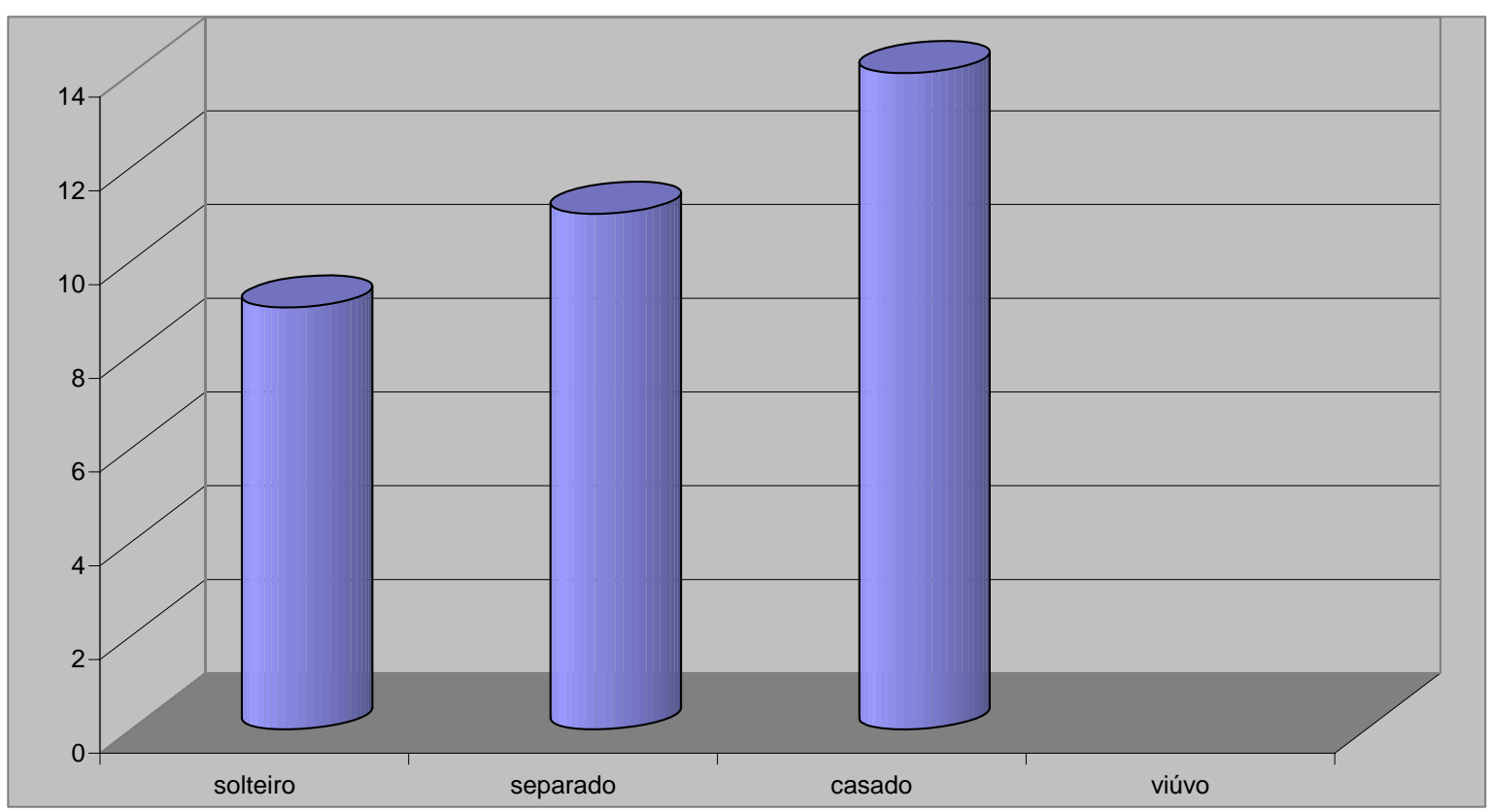

A distribuição da renda familiar mensal da amostra da pesquisa está delineada no gráfico 6 observando-se que a grande maioria 67\% relatou ganhar acima de 12 salários mínimos por mês. 


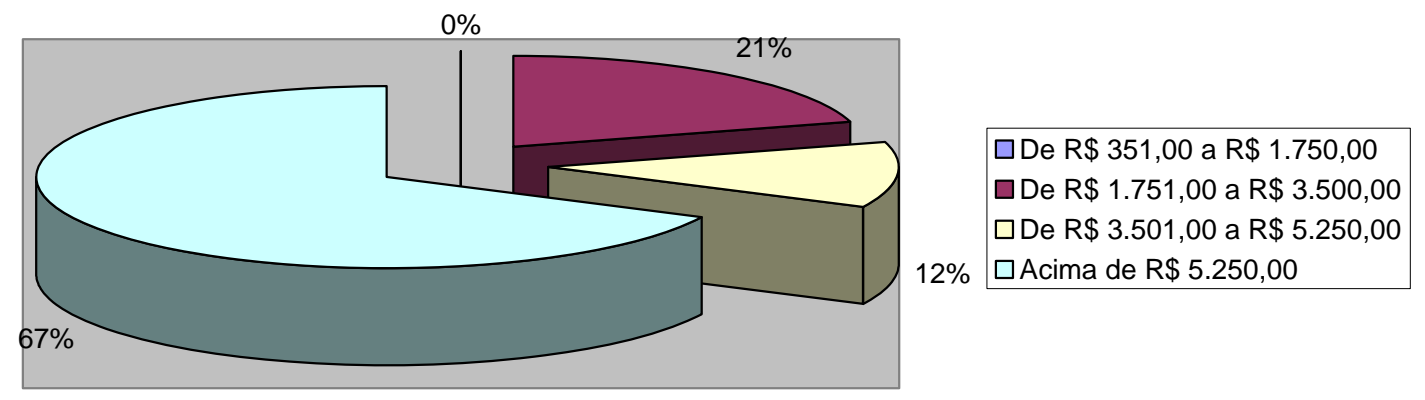

Gráfico 6 - Renda Mensal dos respondentes Fonte: Elaborado pela autora em adaptação por Oliveira (2006)

Tabela 1

Porcentagem dos resultados da escala Likert

\begin{tabular}{|l|c|c|c|c|c|}
\hline & DT & DP & NCND & CP & CT \\
\hline Considera-se leal & $20 \%$ & $17 \%$ & $17 \%$ & $17 \%$ & $29 \%$ \\
\hline Primeira opção de escolha & $14 \%$ & $11 \%$ & $35 \%$ & $14 \%$ & $26 \%$ \\
\hline Não freqüenta outro se o restaurante está disponível & $26 \%$ & $03 \%$ & $28 \%$ & $26 \%$ & $17 \%$ \\
\hline Espera alta qualidade & $03 \%$ & $00 \%$ & $14 \%$ & $23 \%$ & $60 \%$ \\
\hline Chance alta de servir como escolha de restaurante & $11 \%$ & $06 \%$ & $23 \%$ & $14 \%$ & $46 \%$ \\
\hline Identifica a marca entre os concorrentes & $09 \%$ & $09 \%$ & $20 \%$ & $29 \%$ & $33 \%$ \\
\hline Conhece bem a marca & $11 \%$ & $03 \%$ & $09 \%$ & $46 \%$ & $31 \%$ \\
\hline Características da marca vêm à cabeça & $09 \%$ & $20 \%$ & $11 \%$ & $23 \%$ & $37 \%$ \\
\hline Lembra o símbolo ou logotipo da marca & $06 \%$ & $00 \%$ & $26 \%$ & $48 \%$ & $20 \%$ \\
\hline Vale a pena freqüentar mesmo que haja outro igual & $09 \%$ & $06 \%$ & $11 \%$ & $20 \%$ & $54 \%$ \\
\hline $\begin{array}{l}\text { Prefere a marca mesmo com outras com características } \\
\text { iguais }\end{array}$ & $11 \%$ & $03 \%$ & $23 \%$ & $40 \%$ & $23 \%$ \\
\hline Prefere esse restaurante a outro tão bom quanto. & $20 \%$ & $03 \%$ & $29 \%$ & $11 \%$ & $37 \%$ \\
\hline
\end{tabular}

Fonte: Elaborado pela a autora em adaptação por Oliveira (2006). Legenda: DT - Discordo totalmente

DP - Discordo parcialmente

NCND - Nem concordo, nem discordo

$\mathrm{CP}$ - Concordo parcialmente

CT - Concordo totalmente 
Para um melhor entendimento da pesquisa, já que foi utilizado para tratamento dos dados planilha de Excell, considerou-se as opções de escolhas de discordo totalmente e discordo parcialmente como não nas respostas das questões, nem concordo nem discordo como neutro e concordo parcialmente e concordo totalmente como sim. Portanto, a pesquisa mostrou que os clientes consideram-se leais à marca da rede gastronômica com $46 \%$ de satisfação; têm como primeira opção de escolha em restaurante com 40\%; não freqüenta outro restaurante se um dos empreendimentos da rede está disponível com 43\% do total apurado; $73 \%$ dos pesquisados esperam alta qualidade nos serviços prestados pela rede; $60 \%$ afirmam que tem uma chance alta de servir como escolha de restaurante; $62 \%$ identificam a marca entre os concorrentes; 77\% conhecem bem a marca; $60 \%$ afirmam que as características da marca vêm à cabeça; 68\% lembram o símbolo ou logotipo da marca; 74\% acreditam que vale a pena freqüentar um dos empreendimentos da rede mesmo que haja outra opção igual; 63\% preferem à marca mesmo com outras opções com características iguais e 48\% prefere a rede gastronômica mesmo que haja outro tão bom quanto.

De acordo com Sloan (2005) os indivíduos acreditam que comer fora é uma opção e esperam que os restaurantes os ajudem a realizar certos desejos. Esses não são simplesmente “desejos objetivos" - de boa comida e bom atendimento -, mas expectativas de que os restaurantes satisfaçam desejos emocionais mais profundos por status e pertencimento. O fato de diversos tipos de restaurantes afirmarem que são capazes de proporcionar essa satisfação, e na verdade incorporar esses desejos, no entanto, revela como as emoções são transformadas em mercadorias e revendidas aos indivíduos como se fossem itens de consumo.

A pesquisa mostrou que os consumidores conhecem bem a rede gastronômica e são fiéis à marca. 


\section{CONCLUSÕES E RECOMENDAÇÕES}

O presente trabalho teve como objetivo, analisar os possíveis fatores intervenientes na decisão e fidelidade à marca no caso de um restaurante do tipo gastronômico em Brasília.

A partir de tudo o que foi esclarecido e pesquisado sobre o tema abordado: podem ser considerados os seguintes pontos:

Os consumidores esperam alta qualidade nos serviços prestados pela rede; o cliente conhece bem a marca; afirmam que as características da marca vêm à cabeça; acreditam que vale a pena freqüentar um dos empreendimentos da rede mesmo que haja outra opção igual; preferem a rede gastronômica mesmo que haja outro tão bom quanto.

Conforme apresentado na revisão literária é mais fácil e menos oneroso reconquistar um cliente do que encontrar um novo.

Constatou-se que a empresa apresenta na sua maioria respostas positivas, contudo, podem ser realizadas melhorias. Portanto, algumas sugestões e recomendações foram propostas, em busca de sanar ou reduzir a relativa insatisfação apresentada em alguns pontos. Beneficiando assim, os clientes, a empresa e possibilitando qualificação e crescimento profissional aos seus funcionários.

A crescente preocupação com a saúde constitui uma reação racional a várias questões alimentares que surgiram nas últimas décadas. O fato de muitas doenças modernas, como obesidade, doenças cardiovasculares e até mesmo determinados tipos de câncer, estarem ligadas ao consumo de alimentos é uma preocupação constante tanto nos países desenvolvidos quanto nos em desenvolvimento (Hoffman, 2001). Particular atenção, contudo, está sendo dada a duas dimensões da melhoria de qualidade dos alimentos: uma relativa à saúde, com 
ênfase no aprimoramento dos sistemas de produção, e outra relativa ao paladar, que considera não só o valor do alimento para a vida, mas também a sua dimensão fisiológica e emocional

Diante da realidade evidenciada na empresa existe uma oportunidade para fortalecer a sua marca no mercado, podendo corrigir falhas que estejam prejudicando as operações dos negócios, proporcionando assim uma maior transparência nas negociações com os clientes. Conforme foi enfocado neste estudo, toda e qualquer ação de marketing voltada para a satisfação do consumidor é válido com o intuito de decisão e fidelidade à marca no caso de um restaurante do tipo gastronômico em Brasília. Importante também um enfoque à saúde, utilizando uma nova pesquisa para saber a importância do alimento saudável para o consumidor que freqüenta esse tipo de estabelecimento

Considera-se, todavia, que essa pesquisa foi muito enriquecedora em todos os aspectos, desde a revisão literária, até o nível de significância das conclusões obtidas para explicar a importância de se entender o poder da marca ao se abrir um estabelecimento comercial; investigar qual o perfil do consumidor na escolha da marca pesquisada; avaliar a percepção do consumidor em relação à marca estudada, como recurso capaz de contribuir para a sobrevivência das empresas e profissionais da área.

Sob expectativa, este projeto que aqui se encerra, buscou esclarecer determinar a avaliação do consumidor em relação a identidade divulgada pela marca

Por tratar-se de tema de tamanha complexidade, com tão significativo nível de influência sobre determinados fenômenos organizacionais, a pesquisa dos possíveis fatores intervenientes na decisão e fidelidade à marca constitui-se num produto inacabado, que requer ainda muitos estudos e, quando possível, generalizações. 
Durante a realização do mesmo percebeu-se, ao consultar os diversos autores que abordam a temática, o quanto é importante o aprofundamento do assunto como forma de identificar possibilidades de melhoria nas empresas.

Assim sendo, o referido trabalho sugere que seja implementado as sugestões aqui citadas e mediante resultados aplicar nova pesquisa no intuito de mensurar as mudanças inerentes ao tema. 


\section{REFERÊNCIAS}

AZEVEDO, A. Estratégias de construção de Marcas Portuguesas - Desenvolvimento e Aplicação do Modelo da Resposta Auto-Congruente à Publicidade, Tese de Doutoramento, Braga: Universidade do Minho. 2003.

BALDAUF, A., CRAVENS, K. S., BINDER, G. Performance consequences of brand equity management: evidence from organizations in the value chain. Journal of Product \& Brand Management, v. 12, n.4, p. 220-36, 2003

BATESON, John. EG; HOFFMAN, K. D. Marketing de services. Tradução Lucia Simonini 4 ed. Porto Alegre: Bookman, 2001. 495p.

BARNES, James G. Segredos da Gestão pelo relacionamento com os clientes. Rio de Janeiro: Qualitymark, 2002.

BROWN, S. A. CRM - Customer Relationship Management - Uma ferramenta estratégica para o mundo e business. São Paulo: Makron Books, 2001.

COBRA, Marcos. Vendas Edição Ibero - Americana, São Paulo, Editora \& Marketing, 2001.

CHERNATONY, L. Brand Management Through Narrowing the Gap Between Brand Identity and Brand Reputation, Journal of Marketing Management, Vol. 15, 1999.

DAYAN, E. Restaurante: técnicas de serviço. Caxias do Sul: 1990.

Educs. DELleUSE, Gilles. Post-Scriptum Sobre As Sociedades De Controle. Conversações: 1972-1990. Rio de Janeiro: Ed. 34, 1992. Disponível em: http://br.geocities.com/polis_contemp/dossie_deleuze_textos/post_scriptum_controle.pdf.

Acesso em 20 de jun de 2008.

ENGEL, J. F.; BLACKWELL, R. E. e MINIARDI, P. W. Comportamento do consumidor. Rio de Janeiro: LTC Editora, 2000

HECK, Marina de Camargo.; Comer como atividade de lazer. Estudos Históricos, CPDOC/FGV, Rio de Janeiro, n 33, 2004.

HOFFMAN, D. J. Obesity in developing countries: causes and implications. Food, Nutrition and Agriculture. FAO Publications, 2001.

GIL, Antonio Carlos. Como elaborar projetos de pesquisa. São Paulo: Atlas, 1991. 
GOBÉ, Marc. A emoção das marcas - Conectando marcas às pessoas. Rio de Janeiro: Negócio, 2002.

KOTLER, Philip. Administração de marketing. 5ºd. São Paulo: Atlas, 1998.

Marketing essencial: conceitos, estratégias e casos. 2. ed. São Paulo: Pearson Education do Brasil, 2005.

Marketing para o século XXI. 7ed. São Paulo: Futura, 2000.

Administração de Marketing. São Paulo: Atlas, 1996.

MAlHotra, N. K. Pesquisa de marketing: uma orientação aplicada. Porto Alegre: Bookman, 2001.

MARTINS, José; A Natureza Emocional da Marca: como encontrar a imagem que fortalece sua marca. $4^{a}$ Ed. São Paulo: Negócio Editora, 1999.

MAHFOOD, Phillip. E. Transformando um cliente insatisfeito em um cliente para sempre. São Paulo: Makron Books, 1994.

MOUTELLA, Cristina. Fidelização de Clientes como Diferencial Competitivo. Disponível em : http://www.gerenciadordevendas.com.br/gerenciador/artigo010.htm acesso em 29 jun. 2008.

MARX, Karl. Manuscritos econômicos-filosóficos. In.:Manuscritos económico-filosóficos. Trad. Artur Mourão. Lisboa, Edições Setenta, 1989.

OLIVEIRA, Daniela Ferro. Mensurando o valor da marca, a reputação e a identidade no setor automotivo. Dissertação de mestrado apresentada a Universidade Federal de Minas Gerais. 2006.

OLIVEIRA, Sílvio Luiz de Oliveira. Tratado de Metodologia Científica: projetos de pesquisas, TGI; TCC, monografia, dissertações e teses. 2. ed. São Paulo: Pioneira, 1997.

PALADINI, E.P. Controle de qualidade: Uma abordagem abrangente. São Paulo, Editora Atlas, 1990.

PAIXÃO, Cristiane de Oliveira Roque. A Estratégia de Serviço Agregado Na Indústria Automobilística: O Caso Confiat. Dissertação de mestrado. Florianópolis, 2002. Disponível em: http://teses.eps.ufsc.br/defesa/pdf/10261.pdf. Acesso em 30 de jun de 2008.

POWERS, T. \& BARROWS, C. Administração no Setor de Hospitalidade. São Paulo: Atlas. 2004. 
PORTER, M.E. Vantagem Competitiva: Criando e Sustentando um Desempenho Superior”. Editora Campus, 1989, 289 p.

PINHO, José Benedito. O poder das marcas. São Paulo: Summus, 1996.

SANTOS, Laymert Garcia dos. "Consumindo o futuro." São Paulo: Folha de São Paulo, 27 de março de 2000. Disponível em: http://www.race.nuca.ie.ufrj.br/journal/s/santos10.doc. Acesso em 30 de jun de 2008.

SALZER-MÖRLING, M. e STRANNEGARD, L. "Silence of the brand", European Journal of Marketing, Vol. 38, n 1/2, 2004.

SLOAN, D. Gastronomia, restaurantes e comportamento do consumidor. Barueri - SP: Editora Manole, 2005.

SPANG, Rebecca L. A Invenção do Restaurante. Rio de. Janeiro: Record, 2003.

STRUNCK, Gilberto Luiz. Como criar identidades visuais para marcas de sucesso. Rio de Janeiro: Rio Books, 2001.

TAVARES, Mauro Calixta. A força da marca - como construir e manter marcas fortes. São Paulo: Editora Harbra, 1998.

VIEIRA, Stamilir. Marca - o que o coração não sente os olhos não vêem. São Paulo: Ed. PUC-Rio/Ed. Loyola, 2002.

WALKER, J. \& LUNDBERG, D. 2003. O restaurante: conceito e operação. São Paulo: Bookman.

YIN, R. K. Case study research: design and methods. Newbury Park: Sage, 1988.

YOO, B., DONTHU, N. Developing and validating a multidimensional consumer-based brand equity scale. Journal of Business Research, v. 52, p. 1-14, 2001. 


\begin{abstract}
APÊNDICE
Questionário aplicado

Pesquisa: Valor da marca agregado a restaurante do tipo Gastronômico
\end{abstract}

Agradeço desde já a sua resposta a este questionário. O objetivo é conhecer algumas informações do consumidor dos empreendimentos da rede de restaurantes do tipo gastronômico em Brasília. Por isso, solicito a você que responda TODAS as questões com atenção. Reproduzindo suas opiniões o mais fielmente possível. Ressalto que todas as informações serão mantidas em sigilo. Aproveitadas única e exclusivamente para uso do acadêmico, e que sua identidade será preservada.

Para cada item abaixo, assinale com um $\mathrm{X}$ o número de 1 até 5 que representa aquilo que você sente com relação aos empreendimentos , sendo

\title{
1 = Discordo Totalmente; 2 = Discordo Parcialmente; 3 = Nem concordo, nem discordo; 4 = Concordo Parcialmente e 5 = Concordo Totalmente.
}

\begin{tabular}{|c|c|c|c|c|c|}
\hline & \multicolumn{2}{|c|}{$\begin{array}{c}\text { DISCORDO } \\
\text { TOTALMENTE }\end{array}$} & \multicolumn{3}{|c|}{$\begin{array}{l}\text { CONCORDO } \\
\text { TOTALMENTE }\end{array}$} \\
\hline & 1 & 2 & 3 & 4 & 5 \\
\hline \multicolumn{6}{|l|}{ 1) Eu me considero leal aos empreendimentos da rede } \\
\hline \multicolumn{6}{|l|}{ 2) A marca dos empreendimentos da rede é a minha primeira opção de escolha em restaurante } \\
\hline \multicolumn{6}{|l|}{ 3) Eu não vou a outro restaurante se um dos empreendimentos da rede está disponível } \\
\hline \multicolumn{6}{|l|}{ 4) Eu espero que a qualidade da marca dos empreendimentos da rede seja extremamente alta } \\
\hline \multicolumn{6}{|l|}{$\begin{array}{l}\text { 5) A chance de que a marca dos empreendimentos da rede sirva para mim como escolha de restaurante é } \\
\text { muito alta }\end{array}$} \\
\hline \multicolumn{6}{|l|}{ 6) Eu posso identificar a marca dos empreendimentos da rede entre os concorrentes } \\
\hline \multicolumn{6}{|l|}{ 7) Eu conheço bem a marca dos empreendimentos da rede } \\
\hline \multicolumn{6}{|l|}{ 8) Algumas características da marca dos empreendimentos da rede vêm à minha cabeça } \\
\hline \multicolumn{6}{|l|}{ 9) Eu rapidamente posso lembrar o(s) símbolo(s) ou logotipo(s) da marca dos empreendimentos da rede } \\
\hline \multicolumn{6}{|l|}{ 10) Vale a pena freqüentar as opções dos empreendimentos da rede, mesmo quando é igual às outras } \\
\hline \multicolumn{6}{|l|}{$\begin{array}{l}\text { 11) Mesmo que outros restaurantes tenham as mesmas características, eu prefiro escolher um dos } \\
\text { empreendimentos da rede }\end{array}$} \\
\hline $\begin{array}{l}\text { 12) Mesmo que haja outro restaurante tão bom quanto, eu prefiro escolher um dos empreendimentos da } \\
\text { rede }\end{array}$ & & & & & \\
\hline
\end{tabular}


Para as questões seguintes, marque um $X$ a que melhor representa sua situação:

36) Há quanto tempo você freqüenta algum dos empreendimentos da rede?

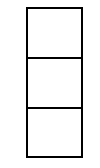

1. Menos de 1 ano

2. Entre 1 e 5 anos

3. Entre 5 e 10 anos

37) Sexo

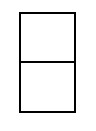
1. Feminino
2. Masculino

38) Qual o seu nível de escolaridade?

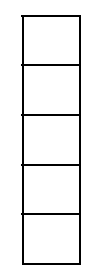

1. Primeiro grau completo

2. Segundo grau completo ou incompleto

3. Superior incompleto

4. Superior completo

5. Pós-graduação

39) Qual a sua faixa etária?

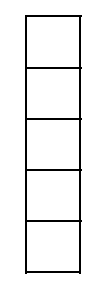

1. Menos de 20 anos

2. 21 a 30 anos

3. 31 a 40 anos

4. 41 a 50 anos

5. Mais de 50 anos

40) Qual o seu estado civil?

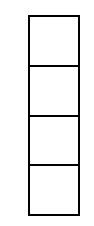

1. Solteiro

2. Separado ou divorciado

3. Casado ou vive junto

4. Viúvo

41) Qual a sua renda mensal familiar bruta (o somatório de todos os rendimentos embolsados por todos os membros da família)?

1. de $\mathrm{R} \$ 351,00$ a $\mathrm{R} \$ 1.750,00$

2. de $\mathrm{R} \$ 1.751,00$ a $\mathrm{R} \$ 3.500,00$

3. de $\mathrm{R} \$ 3.501,00$ a $\mathrm{R} \$ 5.250,00$

4. acima de $\mathrm{R} \$ 5.250,00$ 